\title{
TECNOLOGIAS AUDIOVISUAIS NA CONSTRUÇÃO DE NARRATIVAS ETNOGRÁFICAS, UM PERCURSO DE INVESTIGAÇÃ ${ }^{1}$
}

\author{
Ana Luiza Carvalho da Rocha
}

\begin{abstract}
"Mas enquanto considerarmos mais profundamente o ser e a substância daquilo que somos imutáveis, ficaremos cientes de que não existe a morte, não só para nós como para qualquer substância, enquanto nada diminui substancialmente, mas tudo , deslizando pelo espaço infinito, muda de aparência".
\end{abstract}

(Giordano Bruno, Sobre o Infinito)

\section{Introdução}

Perscrutar os usos da imagem na produção dos saberes antropológicos encerra uma pergunta complexa para o próprio antropólogo: Qual o lugar que ocupa o "dinamismo prospectivo" da imaginação criadora no projeto de entendimento humano?

A Antropologia tem hesitado freqüentemente entre enfocar o sentido da imagem a partir de uma derivação lógica de representação do mundo social ou adotá-la como topos aberto à estética do imaginário na busca de realização da obra etnográfica. Retomando a simbólica da imagem como reveladora de algo mais do que ela encerra como "coisa", este artigo ensaia investigar a força da imagem técnica na construção de narrativas visuais em Antropologia, em meio a outros suportes tecnológicos - a oralidade, a escrita, as redes eletrônicas.

Herdeira dos saberes científicos produzidos no berço de uma civilização iconoclasta, na qual o conhecimento da totalidade do objeto se desvinculou progressivamente da participação da totalidade do sujeito, a Antropologia tem se furtado a refletir sobre o problema epistemológico acerca do lugar que a imaginação criadora ocupa na construção de suas narrativas etnográficas. Da mesma forma, esta matriz disciplinar tem evitado o debate em torno da conjunção de juízos estéticos e reflexivos nas suas adoções metodológicas.

Este artigo é uma tentativa de abordar o tema da construção e análise da imagem técnica, tendo como ponto de reflexão a Antropologia do imaginário, dedicando especial atenção aos modos de composição empregados pela Antropologia visual para a realização de suas etnografias.

O primeiro eixo de indagações que gostaria de trazer à luz diz respeito às implicações que decorrem desta tentativa de situar o debate em torno de tais suportes tecnológicos do

1 KOURY, Mauro. (Org.). Memória e Imagem. João Pessoa, UFPB, e Campinas, Papirus. 
pensamento em Antropologia ${ }^{2}$ a partir de uma reflexão sobre o lugar do Imaginário na produção/geração de narrativas etnográficas para além da história de suas técnicas e métodos.

Nos dias de hoje, é preciso enfrentar o problema da corrosão de alguns paradigmas dos saberes antropológicos ao se tentar elucidar os laços íntimos que unem a Antropologia aos cânones de uma filosofia racionalista, que busca isolar a ação da imaginação criadora no âmbito de suas produções em favor do postulado universal do Cogito face a seus tours e détours no sentido de explicitar os fundamentos próprios das crenças e do conhecimento.

Um segundo aspecto, derivado do anterior, diz respeito às ressonâncias do mundus imaginalis $^{3}$ na equilibração das operações cognitivas realizadas pelo sujeito humano, o que implica rever-se aqui a adesão da matriz antropológica às regras de uma razão cartesiana e positiva que pesa consideravelmente no aprisionamento dos saberes antropológicos aos regimes da consciência.

Longe de situar o trajeto de formação dos juízos críticos e reflexivos no corpo das manifestações culturais das sociedades humanas, a Antropologia, ao tomar como prerrogativa de lisibilidade da obra etnográfica unicamente sua unificação formal e estrita coerência racional, despreocupa-se com a função de equilibração do conhecimento capaz de reunir homem e mundo.

Não se trata, neste artigo, da adoção do argumento naif a propósito do rechaço ao concurso da imaginação poética no âmbito da produção etnográfica, mas do enfrentamento das esferas do simbolismo imaginário no processo de formulação dos conceitos científicos. ${ }^{4}$ Nestes termos, refiro-me aqui apenas parcialmente a alguns impasses que enfrentam, hoje, os antropológos que usam as tecnologias audiovisuais na produção de suas obras etnográficas e que os obrigam à releitura dos clássicos em Antropologia, inclusive no âmbito da antropologia pós-moderna e da sua crítica à etnografia realista.

Assim procedendo, não tenho nenhuma pretensão de determinar e enunciar, em termos claros e precisos, a natureza das formas de entendimento da vida social com as quais

\footnotetext{
${ }^{2}$ Neste ponto, persigo neste artigo algumas considerações de P. Lévy, As Tecnologias do Pensamento, RJ, Ed.34, as quais considero pertinentes ao tema em pauta.

${ }^{3}$ Expressão retirada da obra de H. Corbin, “ Mundus imaginalis ou l'imaginaire et 'imaginal' ". In Cahiers International du Symbolisme, Paris, 1964. na qual o autor tece comentários à faculdade de intuição imaginativa e à imaginação criadora como traços da realidade mental do conhecimento, uma vez que se o pensamento se descola das coisas ele não pode prescindir da existência daquilo que o faz desprender-se, a faculdade de aceder às imagens e de criá-las enquanto cria-se a si mesmo. No sentido apontado por este autor, o mundus imaginalis prova ao espírito humano sua existência, tendo a imaginação criadora um valor gnóstico.

${ }^{4}$ Embora não seja o tema central do artigo, valeria a pena considerar aqui o fato de a narrativa etnográfica, tanto quanto a literária e a histórica, não se afastar do tema do Imaginário, já que trabalha no plano da linguagem, nos interstícios existentes entre os fatos brutos e a sua explicação/compreensão. Neste sentido, um "relato etnográfico", mesmo aquele que não se gera através dos meios audiovisuais, significa e antecipa outra coisa que não ele próprio, remetendo à interpretação, ou seja, a um sistema de referência indireto de símbolos.
} 
os antropólogos operam. ${ }^{5}$ Longe de uma empreitada faustiana, o que se sugere é preservar um pouco mais de "suplemento de alma" ao processo de produção de conhecimento em Antropologia. Ironicamente, talvez este ponto de reflexão seja o que faz despontar, para o pior ou o melhor, a importância do uso das tecnologias audiovisuais no campo dessa matriz disciplinar, ou seja, como parte de um trajeto de recondução da Antropologia a sua vocação de ser mais uma obra, entre tantas, da démarche da cultura humana como tal.

\section{A estética ocidental e o assujeitamento das imagens ao logos racional}

Iconofilia ou iconofobia, qual a maneira de se compreender, nos dias atuais, o uso das tecnologias audiovisuais numa pesquisa antropológica? De tal forma traída em seu arsenal simbólico, a imagem, pela rica abordagem estética de seus efeitos de "regressão onírica em detrimento da consciência analítica", de "impressão de realidade em detrimento da transgressão do real", podem representar, num certo sentido, uma ameaça de perda de significação para a obra etnográfica em sua anterioridade à língua e, sobretudo, à escrita. ${ }^{6}$

Para fazer avançar tal perspectiva ameaçadora a propósito da imagem técnica, os postulados epistemológicos que subjazem às obras etnográficas precisam adotar uma posição reducionista em relação à imaginação criadora, da qual resulta boa parte do patrimônio das obras da cultura humana que não estão situadas no plano do conhecimento positivo, submetendo a imagem técnica a uma segregação e classificação no interior do discurso científico. Dedução ao plano da experiência, em Antropologia a crítica às tecnologias audiovisuais sofre, muitas vezes, as limitações do racismo cacteriológico, oriundo do empirismo lógico ${ }^{7}$ que impregna os saberes antropológicos e que tende a reduzir as peripécias semânticas ao universo concreto de suas técnicas. ${ }^{8}$

Gravitando em torno de um Cogito formal, dos caracteres de necessidade racional e de estruturação da experiência, o emprego dos meios audiovisuais nas etnografias estaria, assim, perigosamente preso às armadilhas de um ordem lógica linear, situada na superfície da

\footnotetext{
${ }^{5}$ De acordo com o que assinala E. Cassirer, A filosofia do Iluminismo, Campinas, Ed. UNICAMP, 1994, p 386, na estrutura intelectual histórica do séc. XVII à qual, de muitos modos, acredito, estamos ainda assujeitados, a arte, como a ciência, coloca os "sinais" dos objetos no lugar dos objetos e só se distingue dela pelo uso que faz dos mesmos". Isto, no contexto aqui apresentado, pode ter derivações, no caso da etno-grafia, principalmente no que se refere ao campo dos recursos audiovisuais, uma vez que aí se presencia uma "razão" estética que, pelo concurso do "naturalismo" de sua representação, pode ser aludida à precisão e determinação da coisa representada.

${ }^{6}$ Cf. A Leroi-Gourhan, Le geste et la parole, vol I e II., Paris, Albin Michel, 1964.

7 Cf. Piaget, A Epistemologia Genética, SP, Abril Cultural, 1978, p.42, um dos "dogmas” do empirismo lógico seria a "distinção radical entre os juízos analíticos e os sintéticos" ao subtrair das experiências os processos de abstrações.

${ }^{8}$ Aproprio-me aqui de algumas reflexões que faz P. Riceour, Tempo e.. op. cit., sobre as configurações temporais que a história e a ficção estabelecem juntas para refletir sobre a "compreensão configurante" que encerra a produção de narrativas visuais em Antropologia, onde a imagem se desprende de sua seqüencialidade episódica do tempo, tal como é apresentada, e desliza para a sua qualidade narrativa enquanto expressão da imaginação criadora.
} 
narrativa, em que as regras e os modelos das estruturas operatórias naturais do pensamento e da linguagem são reivindicados em detrimento das estruturas formais do pensamento, que fazem com que aquilo que está sendo narrado adquira autonomia e fecundidade próprias.

Ora, a imaginação criadora, no plano dos juízos analíticos, contem uma intenção formal, dinâmica e material que influencia a construção do pensamento na medida em que é ela que permite à figura humana a sua reconciliação equilibradora com o mundo no plano da acomodação subjetiva do real e da assimilação objetivante do sujeito humano à ordem do mundo. ${ }^{9}$ Nos termos do subjetivismo bachelardiano, poder-se-ia dizer que a construção de narrativas etnográficas em Antropologia visual depende, como os demais saberes científicos, de a imagem aflorar fora do próprio homem, aparecendo, ao mesmo tempo, enquanto evento singular da objetivação do pensamento e fenômeno transubjetivo nos termos da lógica de seus conjuntos de estruturas formais.

Além do estágio de desenvolvimento das técnicas e dos meios de expressão, das pressões de contextos sócio-históricos e das demandas estéticas de épocas, há, portanto, estruturas subjacentes fundamentais que entram em jogo na composição formal do pensamento científico e que configuram o próprio trajeto de construção do conhecimento humano. No plano de uma epistemologia genética, poder-se-ia dizer que a imaginação participa das estruturas lógico-formais do pensamento científico, uma vez que através dela é que o sujeito humano se faz sujeito epistêmico. ${ }^{10}$

Considerando-se que, no plano formal, a produção etnográfica em Antropologia é o resultado da competência do antropólogo em reunir, através do concurso da imaginação, classes de acontecimentos e incidentes dispersos registrados em suas idas a campo, integrando-as numa totalidade una e completa, nada há de surpreendente em associar a abstração refletidora necessária à formalização de sua obra à sua capacidade de narração.

No desafio de criar uma história composta por classes de acontecimentos e situações e narrada através dos caracteres e das ações particulares de seus personagens, dispostas numa totalidade coerente, através da imagens-movimento, ${ }^{11}$ é que o antropólogo faz do uso das

\footnotetext{
${ }^{9}$ Importante mencionar aqui os comentários de P. Ricoeur, na obra $O$ si-mesmo...op.cit., Cap. III, sobre a "semântica da ação sem agente", onde o autor, a partir das relações entre teoria da linguagem e a teoria da ação, afirma ser a descrição equivalente à explicação causal quando se toma a intencionalidade que move o agente (da ação) em termos de racionalização.

10 Segundo Bachelard, La poétique de la rêverie, Paris, PUF, 1993, o onirismo intelectual é condição da integridade do conhecimento. Desta forma, o pensamento humano, operando através das imagens, é conhecimento de si; fruto de uma atividade onírica, resulta que tal conhecimento se processa no centro de nosso Eu sonhador, sendo lá, ainda, que o Cogito ganha suas raízes mais profundas.

${ }^{11}$ Cf. Expressão com a qual G. Deleuze, L'image-temps, Paris, Editions Minuit, 1985, opera as distinções entre a imagem enquanto prisioneira das exigências das situações e encadeamentos sensório-motores (imagem-ação), que afirma a indiscernibilidade entre o real e o imaginário, e a imagem como constituída por situações puramente óticas e sonoras (imagem-movimento), cuja força estética reside nas indiscerníveis passagens e conversões do real ao imaginário.
} 
tecnologias audiovisuais a expressão de uma poiésis tanto quanto há tempos atrás o cálamo e a pena de ave serviam ao romancista, ao viajante e ao cronista, ancestrais dos antropólogos.

Diferentemente da produção escrita, entretanto, a construção de etnografias através dos meios audiovisuais, pelo mergulho que ela autoriza ao sujeito epistêmico nos seus "efeitos ilusionistas", revela às faculdades humanas o ilimitado campo de criação de sentido, não mais conduzindo, de forma instrutiva, a força das estruturas formais do pensamento humano em direção ao mundo ao mero estado de cópia da realidade.

Assim, a imagem técnica (imagens fotográfica, videográfica ou fílmica), para além da visibilidade de seus mecanismos de enunciação para os quais concorre a história técnica da Antropologia visual, é enraizamento e abertura do homem no mundo; ela nasce no interior do próprio fenômeno da linguagem humana, como arranjo e modelagem do ser-para-si da consciência, entretanto, enquanto prótese do pensamento ela é criação, e não apenas aquisição, ao integrar um universo conceptual que não compreende tão somente o real.

\section{Etnografia visual, representações do real e operações cognitivas}

Uma das grandes dificuldades da produção de uma obra etnográfica que tem por fundamento a imagem técnica é a problemática do aparecimento do ser do investigador imerso entre as imagens-cópias ou imagens-simulacros ${ }^{12}$ do mundo das coisas, e de seus efeitos de espelhos, de sombras, na medida dos reflexos do si-mesmo do pesquisador que transparece no ato mesmo da produção/geração de imagens, multiplicando os seus próprios níveis de construção e de reflexão.

Em Antropologia visual, investir no tratamento meramente representacional da imagem técnica seria lhe conceder o papel de simulação do mundo das coisas, sem apreender as operações cognitivas que têm por objeto a imagem, operações que constituem transformações e não apenas a reprodução dos estados das coisas.

Há certamente uma diferença entre a exploração da imagem técnica como fenômeno estável, inspirada nas tradições narrativas realistas ou naturalistas do séc. XIX, e concebê-la aqui na direção da instabilidade dos seus enunciados, das suas estruturas dinâmicas e do processo de abstração daí derivado.

\footnotetext{
${ }^{12}$ Valeria a pena, aqui, retraçar os comentários de E. Subirats, A cultura como espetáculo, SP, Nobel, 1990, sobre as técnicas de reprodução audiovisual e os meios de comunicação de massa no sentido de estabelecer uma sutil diferença no atributo de cópia e simulacro para qualificar a experiência do real a partir da imagem. $\mathrm{O}$ autor amplia essa polêmica ao recolocar o simulacro na ordem de suas preocupações com a construção das obras da cultura humana onde a imagem participa da organização ontológica do próprio mundo, seja pela via da duplicação(imagem réplica), da produção (imagem representação), seja pela reprodução (imagem-ilusão), âmbito do esvaziamento da visão e da experiência do real.
} 
Este panorama anuncia o grau de complexidade de se conceber a imagem técnica nos quadros formais do empirismo lógico da produção do conhecimento em Antropologia, para a qual a solução freqüentemente adotada é reduzir a imagem técnica a uma espécie de não-ser, imagem-fantasmas ou imagem-ilusão, ${ }^{13}$ no sentido de transpor os limites da estruturação do real com base nos erros introspectivos que acompanham os processos parciais de objetivação do sujeito epistêmico.

Em Antropologia, a polêmica dos emprego dos meios audiovisuais na produção/geração de obras etnográficas tem o poder de remontar o passado das raízes filosóficas judaico-cristãs do Ocidente moderno, no interior do qual a imagem se situava como uma espécie de não-ser, quase-objeto, com a qual o pensamento humano confrontar-seia no caminho da Verdade.

Neste caso, a desconfiança que se possa nutrir em torno dos recursos audiovisuais como suporte de narrativas etnográficas lembra o sistema de acusação que os platônicos dirigiam aos sofistas, classificando-os como mágicos ou charlatães, capazes de enfeitiçar por meio de ficções faladas, verdadeiras metáforas visuais que tinham o poder da ilusão.

Paradoxalmente, na contramão dos cânones da epistemologia positiva de onde nasceu, se antes a imagem técnica se apresentava como cópia bem-sucedida da natureza dos fatos e das estruturas naturais do pensamento humano (biológicas e fisiológicas), nos dias de hoje, principalmente através do desenvolvimento das tecnologias virtuais, ela parece oferecer um campo minado para a aquisição do conhecimento positivo, uma vez que, por sua manipulação, acabar-se-ia confundindo o não-ser da imagem-cópia pelo real. ${ }^{14}$

Para se sair desta armadilha, o antropólogo que se inicia nos meios audiovisuais aplicados à construção de narrativas etnográficas em Antropologia, enfrenta o tema da verossimilhança da imagem que produz ou gera a coisa representada, confrontando o "irreal não-ser" da imagem ao não-ser irreal do investigador e de suas estruturas cognitivas. ${ }^{15}$

Aceita-se, então, de bom grado, uma reflexão criteriosa dos artefatos tecnológicos empregados como procedimento capaz de neutralizar o caráter de "artifício" que reveste as narrativas audiovisuais, apostando-se que somente a racionalidade de tipo lógico-dedutivo, de

\footnotetext{
${ }^{13}$ No caso do Ocidente cristão, a posição aristotélica ganha terreno sobre a platônica quando o filósofo reconhece que "não existe pensamento sem imagens", tanto quanto "a alma nunca pensa sem imagens". Imagem não é um 'não-ser', ela depende da sensação e toca o pensamento.

${ }^{14}$ A teoria da semelhança na posição platônica enfrenta aqui o tema de "como a imagem duplica o objeto". A imagemsimulacro é definida como segundo objeto, como irreal não-ser. A imagem (eidôlon) é uma espécie de irrealidade no interior do ser.

${ }^{15}$ Nestes termos, como compreender o papel sintético inicial que a imaginação efetua? Tudo repousa no jogo de saberes: saber empírico ( da sensação, da visão, da imagem) e saberes abstratos e teóricos (do raciocínio, da deliberação, etc.), cf. G. Durand, Science de l'homme et Tradition, Paris, Berg International, 1979.
} 
tendência paracientífica, ${ }^{16}$ aplicada à cadeia de fenômenos da imagem-cópia garantiria a sua legitimidade. Através de uma depuração conceitual, livre das mediações simbólicas que orientam a formação de esquemas e estruturas de pensamento, atingir-se-ia os dados da consciência, justificando-se o emprego da imagem técnica em Antropologia mediante os cânones da razão científica. ${ }^{17}$

Tendo-se feito o expurgo da "louca da casa", supõe-se, então, atingir um grau de distanciamento crítico em relação ao tratamento da imagem técnica como simulação da realidade. Assim, nos termos de um materialismo dogmático, o domínio da produção técnica da imagem, pela consciência do artifício que compõe o relato etnográfico, acaba colocando a imaginação do pesquisador no interior dos jogos de composição "extralingüisticos" que configuram sua narrativa, considerados, a partir daí, como critérios de positividade científica da obra enquanto tal.

Para atingir legitimidade, no interior dos cânones do empirismo lógico da matriz disciplinar de onde frutificam, as narrativas audiovisuais em Antropologia devem, portanto, exorcizar os suportes tecnológicos empregados na construção de obras etnográficas pela via da "compreensão categorial" dos elementos que dão forma a sua experiência. ${ }^{18}$

Neste contexto desfazem-se as armadilhas do pensamento de desconfiança em relação à imagem, para que o antropólogo possa, enfim, adentrar os meandros de um pensamento de aceitação parcial do poder da imaginação criadora em se desprender do real pelo reconhecimento de sua "existência" subjetiva como fonte de verdade. Avança-se rumo a um conceitualismo, onde a imagem técnica é vista como tradução de uma idéia que possui uma realidade na coisa representada e onde se nutrem os juízos reflexivos do investigador. Entretanto, elimina-se aqui o sentido de transcendência que guardava a imagem "para além do ser em dignidade e em força".

A produção técnica da imagem desponta essencialmente como instância formadora de juízos sintéticos e suporte do pensamento crítico na medida em que se torna auxiliar do

\footnotetext{
${ }^{16}$ Seguindo os comentários de Piaget, Sabedoria e Ilusões da Filosofia, Sp, Abril Cultural, 1978, p.126, estar-se-ia aqui no plano de um idéia de racionalidade que pretenderia atingir a totalidade do real, "um modo de conhecimento que atinja o próprio irracional".

${ }^{17}$ Vê-se aqui refletida toda uma controvérsia sobre os vínculos entre o mundo das formas e o mundo das imagens onde, em Platão, a imagem é uma realidade fugidia que remete tanto ao modelo (idéia-paradigma) quanto ao simulacro, sendo que as "idéias" guardam aspectos transcendentes, enquanto em Aristóteles, elas têm um um sentido imanente, "as formas são pensamentos pela faculdade inteligível presente às imagens", cf. H. Védrine, Les Grandes Conceptions de l'Imaginaire, de Platon à Sartre et Lacan . Paris, Librairie Générale Française, 1990.

${ }^{18}$ Seria promissor correlacionar esta investigação aos comentários de E. Cassirer, A filosofia do Iluminismo, Campinas, Ed. UNICAMP, 1994, em especial ao Cap. VII, Os problemas fundamentais da estética, onde o autor aborda a influência da razão crítica na conformação de uma filosofia estética, o que leva progressivamente à conversão do campo da criação artística aos problemas da objetividade (racionalismo estético), do subjetivismo (empirismo estético), do gênio (estética intuicionista) e, finalmente, da sensibilidade (estética sistemática).
} 
Cogito, portanto, veículo e condição necessária de abstração na procura do começo absoluto do conhecimento. ${ }^{19}$

Em Antropologia visual, para imputar critérios científicos às ações e às escolhas estratégicas feitas pelo antropólogo para a produção de uma obra etnográfica, freqüentemente recorre-se à análise das correlações existentes entre os componentes da narrativa e os acontecimentos registrados, segundo as unidades de sentido e as estratégias de ordenamento do real subjacentes que a imagem técnica fornece a propósito do mundo das ações e intenções humanas, mas, sobretudo, a favor da figura realista que ela logra perpetuar.

A "redução fenomenológica" das tecnologias audiovisuais na produção etnográfica contempla, portanto, as armadilhas de uma axiomática formal da escrita aplicada à imagem técnica, isto é, o uso de tais tecnologias acaba repousando sobre regras normativas que permitem ao antropólogo elaborar uma narrativa etnográfica capaz de não contradizer as premissas da objetividade em Antropologia.

Desta forma, a Antropologia visual afasta-se progressivamente do enfrentamento do tema da ligação formal que a obra etnográfica estabelece entre o enlace e o desenlace do seu relato, ligação que entrelaça os registros captados em campo e episódios a serem narrados a partir do desenvolvimento de noções e operações intelectuais, os quais ocupam eixos de temporalidade distintos na forma como a narrativa audiovisual opera com o real.

Isto posto, cabe dizer que a experiência registrada em campo, para além de seu suporte técnico, contem em si uma pré-figuração da narrativa etnográfica na medida em que é duração de um tempo vivido; ela é "indutora de narrativa" pelo caráter dos fragmentos de acontecimentos retidos nos atos de memória do antropólogo, através dos quais ele preenche as lacunas de sentido entre eles, organizando-os segundo uma sucessão dos acontecimentos apenas, e tão somente, a partir da sua consolidação na estrutura do tempo da história a ser narrada. Em Antropologia, a depuração de conceitos e a formação das operações que os sustentam exigem a presença da reversibilidade de seus conteúdos no plano espaço-temporal da construção da narrativa etnográfica.

Entretanto, esforçando-se por ultrapassar antíteses tais como vida e matéria, espaço e tempo, vida interior e ação ou linguagem nascidas no berço do racionalismo ocidental, e mais

\footnotetext{
${ }^{19}$ O pensamento de Hume ilustra o que aqui quer se ressaltar. Para o autor, a ilusão é ao mesmo tempo constitutiva e desenraizamento do ser, só o ato de crer dá às ações humanas sua eficácia. Trata-se, pois, de escolher uma razão ou assujeitar-se à total ausência de razão. A origem de tal ceticismo reside na afirmação de que as crenças fundam o conhecimento de duas formas: de um lado, elas ultrapassam o dado e, de outro, elas estão presentes em qualquer inferência. A crença é, portanto, um dos dados primitivos da consciência através das relações que cria entre o real e as inferências; opõese aqui à sensibilidade e atividade do entendimento, sendo que a imaginação é uma ponte entre ambos, cf. H. Védrine, Les Grandes Conceptions..., op. cit.
} 
ainda seduzida pela mística da estrutura "natural" da linguagem, absorvida pela disseminação da civilização da escrita, a Antropologia pode perder de perspectiva a convergência, no plano da "intratemporalidade" da obra etnográfica, das dimensões discordantes do tempo vivido e do tempo refletido como princípio formalizante de suas descrições pela opção dos absolutos próprios ao sujeito da consciência.

Neste terreno, ao empregar-se os recursos audiovisuais apenas como dados documentais de campo, onde é dado à imagem técnica o poder de ilustrar ou "demonstrar" os acontecimentos vividos em campo, acaba-se submetendo-os à construção de modelos mecânicos que simulam a realidade, perdendo tais tecnologias seu estatuto de geradoras de operações formais do real e de estruturas espaço-temporais, suscetíveis de traduzir dilatações ou contrações ao dado empírico da existência, ao prender-se nos grilhões da descrição das coisas e da estrutura temporal da ação do investigador, que tece ela mesma, por "reduções fenomenológicas” à configuração narrativa.

Há, portanto, uma diferença crucial no uso dos meios audiovisuais. Seja como instrumento de pesquisa, enquanto participando da liberação do "mundo" espaço-temporal do antropólogo na tentativa de estabelecer os absolutos analíticos da sua investigação e atingir a "superfície da consciência empírica". Seja como obra de criação, configurada como operações formais reversíveis, acima da consciência do sujeito individual, livre da própria ação investigativa do antropólogo e de suas impressões subjetivas, em proveito das coordenações gerais da realização da obra etnográfica, isto é, as formas de encaixe, ordenação, correspondências, reunião, que ligam as ações de seus personagens umas às outras, e onde as formalizações do pensamento do antropólogo exprimem as propriedades constitutivas da figuração do real.

No primeiro caso, a imagem técnica participa da semântica da ação do antropólogo "em campo", em detrimento de ser o elemento mediador de uma operação de configuração de uma história, obra do ato de narrar do antropólogo ${ }^{20 .}$ Ela é empregada como parte dos fluxos de consciência do personagem central da história, no caso, o investigador confrontado a sua alteridade, girando em torno dos fatos, das suas ações e dos episódios em que esteve envolvido durante seu trabalho de campo. Aqui, a noção de caráter do personagem central acaba por se sobrepor ao próprio ato do tecer da intriga que o registro etnográfico fornece, via os meios audiovisuais, "chegando a eclipsá-lo" (a imagem alia-se à idéia do realismo, não mais no sentido do "o eu estive lá", mas do "eu estou aqui").

\footnotetext{
${ }^{20}$ Importam-se aqui algumas reflexões de G. Deleuze, L'image-temps, op. cit., p.214, que podem nos auxiliar na discriminação dos diversos usos epistemológicos da imagem em Antropologia visual.
} 
Entretanto, a duração vivida em campo (adequação do relato ao dado empírico) e a construção de uma narrativa (necessidade lógica e axiomática do relato etnográfico em si) não se opõem entre si, ao contrário, agem entre si num jogo dialético de forças de sentido, para além da "análise eidética", que orienta o si-mesmo do antropólogo às simples análises do pensamento antropológico na sua formação e no seu funcionamento. ${ }^{21}$

Ambos os fenômenos dependem de operações cognitivas de distintos níveis que desencadeiam o ato de re-construção do real mediado pela ação e linguagem de "esculpir o tempo". A diversidade de tais fenômenos se processarem supõe uma combinatória entre vida e matéria com base em operações formais reversíveis do pensamento e segundo construções inteligentes sobre o real - pela via tanto da ação, quanto da linguagem -, onde desponta o processo de assimilação acomodadora do sujeito cognoscente do antropológo ao dado empírico.

Poder-se-ia, assim, afirmar diferenças nos estatutos da imagem quando, em Antropologia, enfocamos as tecnologias audiovisuais nos quadros de um problema (construtivismo) e de um teorema (axiomática).

Por um lado, no corpo de preocupações teoremáticas, o uso da imagem técnica em Antropologia prender-se-ia às relações intrínsecas de seus princípios de cientificidade e objetividade e às conseqüências no uso de tais tecnologias para o campo das suas normas.

A função "eidética" da imagem nas narrativas audiovisuais em Antropologia pode ser detectada quando, no plano da construção da obra etnográfica, o antropólogo emprega as tecnologias audiovisuais concebendo-as como imagem especular da enunciação cotidiana, segundo a premissa de que a partir dela é possível demonstrar a vida ordinária de seus personagens. Ou ainda quando insiste na construção da sequiência linear para a composição da narrativa etnográfica enquanto função demonstrativa (teoremática) do "mundo das coisas", acabando por reduzir a causalidade formal dos arranjos simbólicos que dão sustentação ao "tecer da intriga" à ordem finalista de uma causalidade material segundo os efeitos da anterioridade e da posteridade. ${ }^{22}$

Entretanto, como se verá adiante, aparentemente resguardada num positivismo lógico, a obra etnográfica revela, mais uma vez, que em sua estrutura lógico-formal obedece a uma sucessão de unidades de sentido configuradora da narrativa, com o ordenamento da experiência empírica vivida pelo antropólogo em campo seguindo uma descronologização.

\footnotetext{
21 A respeito, ver os comentários de Piaget à obra de Husserl, Sabedoria e Ilusões da Filosofia, SP, Abril Cultural, 1978, pp.140-145.

${ }_{22}$ A propósito de ambas as noções empregadas aqui, ver G. Bachelard, La dialectique de la durée, PUF, Paris, 1989.
} 
Por outro lado, como obra construída, a imagem-técnica se apresenta como problema, fazendo intervir um acontecimento de fora: as propriedades da realidade fenomenal investigada pelo antropólogo, que constituem suas próprias condições de produção e determinam o relato a ser construído. ${ }^{23}$ A imagem técnica exprime, neste contexto, uma nova relação de o pensamento antropológico se apresentar, segundo regras formais exteriores ao código da escrita alfabética, e para além da consciência individual do pesquisador.

Contrariamente ao plano axiomático dos usos das tecnologias audiovisuais em Antropologia, e no plano do seu estatuto como construção de conhecimento, a questão da adequação entre a imagem-técnica e o mundo das ações e das intenções humanas não se reduz à sua afirmação como simulação do real, tampouco à "análise eidética" do eu pensante do antropólogo.

Neste caso, a Antropologia visual não teria por objeto apenas os conceitos antropológicos como tais, mas os valores de suas determinações existenciais no plano da recosntrução do real; o relato etnográfico, revelaria, não por acaso, a intenção enunciadora do antropólogo, fornecendo igualmente elementos importantes para a análise do caráter eminentemente formal que o pensamento e a experiência etnográfica contemplam. ${ }^{24}$

Ao contrário de uma obediência aos modelos axiomáticos da objetividade científica em Antropologia (com base na tecnologia da escrita), o que caracteriza os usos das tecnologias audiovisuais enquanto um problema de investigação antropológica é que tais tecnologias são inseparáveis de uma escolha na forma a ser adotada para a narrativa etnográfica. Numa perspectiva construtivista, tal escolha traz em si não apenas questões metodológicas acerca da "demonstração"” dos elementos normativos da conduta do antropólogo em campo e dos elementos relativos a delimitação do objeto antropológico, enfocados em níveis diferenciais. Trata-se de enriquecer os estágios iniciais das estruturas cognitivas que fundam o relato etnográfico, com base na escrita, integrando-os às novas propriedades da coordenação raciocinada dos conceitos antropológicos para a produção de uma obra etnográfica.

No plano da ação, a imagem técnica coloca para a Antropologia o problema da revisão de seus projetos de conhecimento anteriores, uma vez que, nos dias de hoje, a inovações tecnológicas do pensamento franqueiam a abertura desta matriz disciplinar a novos conjuntos

\footnotetext{
${ }^{21}$ Utiliza-se aqui, livremente, os comentários de G. Deleuze, L’image-temps, op.cit., pp 212-213 , para o caso das análises em pauta.

${ }^{24}$ Cf. ainda G. Deleuze, L'image-temps, op. cit.
} 
possíveis de estruturas operatórias de narrativas etnográficas através de reorganizações sucessivas de seus conceitos, alguns irredutíveis aos precedentes.

Portanto, as formulações construtivas da narrativa etnográfica não se esgotam na tecnologia da escrita. No plano do pensamento e da linguagem, o desafio de se produzir uma obra etnográfica com base nas tecnologias audiovisuais decorre da importância de se exercer uma reflexão sobre a gênese das estruturas cognitivas que formam o conjunto das condições de acesso ao conhecimento em Antropologia, engendrando novas reorganizações em seu campo de conceitos.

\section{Etnografia Visual, da intratemporalidade da narrativa e extemporalidade da}

\section{narração}

As dificuldades sempre enfrentadas ao se incorporar a imagem técnica nas formas iniciais do conhecimento em Antropologia não são sem razão de ser, uma vez que se possa correlacionar tais embaraços a herança do saber antropológico à ortodoxia iconoclasta de um pensamento científico racionalista e positivista, calcado no lugar por ele atribuído à imaginação nas formas de conhecimento elaboradas pela Modernidade triunfante. ${ }^{25}$

Neste ponto, o próprio campo de conceitos da Antropologia visual aparece impregnado com tal tradição de pensamento, onde a imagem aparece desligada da consciência imaginante presente ao sujeito humano; fruto de uma tentativa dos antropólogos de separar suas teorias científicas das produções do imaginário "nativo" pesquisado e do seu esforço em cumprir, fielmente, o metiêr de etnógrafo.

Neste sentido, as estruturas de conhecimento em Antropologia, desde seus estágios mais elementares com o evolucionismo, mostram uma complexificação e elaboração sucessivas, graças a construções auto-reguladoras no plano de sua matriz disciplinar. Semelhante quadro revela que a Antropologia visual, mesmo sem adotar a tecnologia da escrita, tem por desafio contribuir com abstrações refletidoras acerca da grafia "realista" ou do tratamento "naturalista" a propósito das ações humanas, numa constante valorização exacerbada de um logos iconoclasta. ${ }^{26}$

\footnotetext{
${ }^{25}$ As leituras de L. Dumont, Da ideologia Moderna, E. Cassirer, Ensaio sobre o homem e A Tourraine, Crítica à Modernidade, juntamente com a obra de L. Ferry, Homo Estheticus, l'invention du goût à l'âge démocratique, podem aqui ser reveladoras da vinculação entre as noções de indivíduo e de subjetividade nos termos do ideário da Modernidade e o nascimento da estética da razão e da figura do "homem da civilização"que as sustentam.

${ }^{26} \mathrm{O}$ iconoclasmo a que se acha submetido o pensamento ocidental pode ter suas origens mais remotas nas doutrinas religiosas que tomam Cristo como princípio de reversio, ao contrário da creatio, efetuando-se na divinização e deificação dos "objetos sensíveis". Nos termos dos derivados de um pensamento moderno, o que se verifica é que a consequiência histórica do platonismo será recusada, em nome do "pensamento direto", a favor do conceptualismo aristotélico, cada vez mais carregado de empirismo. Cf. G. Durand, Science de l'homme ..., op. cit. e R. Guénon, Orient et Occident, Paris, Ed. De la Maisnie, 1987.
} 
Segundo Bachelard, ${ }^{27}$ sempre que se observa o caso de empobrecimento da imagem, pode-se constatar que a produção de conhecimento que aí se gera orienta-se para um individualismo narcísico na produção intelectual. Diferentemente, o subjetivismo bachelardiano propõe para o âmbito da produção de saberes, com e através do concurso da imaginação criadora, a construção de um conhecimento orientado para um narcisismo cósmico, fator de unidade e amplidão do conhecimento humano.

Cabe aqui refletir sobre o fato de que o concurso da imaginação atua no interior dos diversos sistemas de pensamento, sendo ela, inclusive, que impulsiona a consciência do homem da Ciência a afinar seus conceitos. ${ }^{28}$ Neste sentido, tanto a razão científica quanto a inteligência humana navegam nas águas da grande corrente de um pensamento fantástico humano que veicula ações e pensamentos aos dados da experiência empírica. ${ }^{29}$

O problema acerca da depreciação da imagem técnica nas diversas formas do pensamento antropológico deriva da forma como o pensamento científico processou uma higienização do mundus imaginalis ${ }^{30}$ no interior do logos racional, tratando-o como fenômeno resultante da vacuidade essencial da consciência ao orientar-se progressivamente na busca de um pensamento purificado de imagens.

No campo da Antropologia pós-moderna, a consciência da ilusão, no registro das etnografias, subverteu a convenção adotada para o gênero "realista", motivando o antropólogo a libertar-se do próprio ato interpretativo que incide na produção etnográfica. Neste ponto, a história do romance moderno juntamente à "questão do estatuto narrativo da historiografia" na atualidade pode jogar algumas luzes sobre as fontes da inteligibilidade dos usos da imagem na Antropologia, segundo as exigências de cientificidade e da consciência analítica, e seus reflexos na produção da obra etnográfica através das tecnologias audiovisuais.

Pela exigência do momento, é forçoso se perguntar sobre as condições epistemológicas da produção do conhecimento em Antropologia e se investigar a respeito da especificidade da produção de etnografias que tenham por base a geração de imagens no âmbito das tecnologias audiovisuais. Tomando-se as formas iniciais do relato etnográfico e a

\footnotetext{
${ }^{27}$ Cf. G. Bachelard, La poétique de ...op.cit.

${ }^{28}$ Penso aqui na obra de A Corboz et alli, Ciência e Imaginário, Brasília, Ed. UnB, 1994, onde inúmeros pensadores das ciências exatas revelam a intimidade das relações entre o saber científico e o imaginário no sentido de apresentar as diferentes formas pelas quais o logos se nutre da dinâmica não-racional que significa o "profundo reservatório das imagens e dos mitos".

${ }^{29}$ Cf. G. Durand, Les Structures Anthropologiques de l'Imaginaire, Paris, Dunod, 1984., ciência e mito não podem ser dissociados como supõe o corpo de um sistema de crenças de base evolucionista que tende a hierarquizá-los segundo um processo de maturação progressiva do trajeto antropológico do sujeito humano.

30 Expressão cunhada por H. Corbin, "Mundus imaginalis ou l'imaginaire et 'imaginal", in Cahiers International du Symbolisme, n• 6, 1964, para traduzir o mundo das imagens como verdadeiro termo mediador entre a criação material (acidente exterior) e o ato criador (ordem interior).
} 
elaboração sucessiva de suas estruturas, trata-se de elaborar novas formas de narrativas a partir do "prolongamento das abstrações refletidoras já atuantes no desenvolvimento do pensamento" antropológico, no sentido "noético de uma reorganização necessitada pela reconstrução das ligações anteriores" num novo plano, o das narrativas etnográficas visuais. ${ }^{31}$

Os problemas da verossimilhança (e a presumida literalidade da imagem técnica) na descrição das ações humanas em sua verdade cotidiana, a busca da fidelidade à experiência (pelo uso de autobiografias e história oral), o imediatismo sugerido pelos "efeitos de ilusão de proximidade" que a transcrição quase simultânea dos sentimentos experimentados e das circunstâncias registradas através das tecnologias audiovisuais merecem ser analisados aqui à luz dos prolongamentos das estruturas formais da escrita, fundadas na idéia da sua simulação de um pensamento "natural" no âmbito da imagem técnica.

Muitas vezes, o processo de axiomatização da imagem técnica no plano da simulação das estruturas naturais do pensamento (biológicas e fisiológicas) se explicitam aos olhos do antropólogo apenas no momento da montagem que antecede a estrutura a ser adotada para o relato etnográfico em filme, fotografia ou vídeo, quando a obra ultrapassa o âmbito teoremático da pesquisa antropológica e atinge seu grau maior de complexidade enquanto unidade/totalidade.

A "decupagem" mais detalhada da ação (muitas vezes a partir dos efeitos de intercalação de planos) e, logo após, o seu arranjo segundo suas relações de contigüidade no espaço e de continuidade no tempo, pela via da montagem que organiza as sequiências de imagens escolhidas para narrar o "fato etnográfico", desvendam ao próprio antropólogo não só os jogos simbólicos da linguagem como elemento chave para recuperar a "naturalidade" dos acontecimentos agenciados, o fluir da história narrada, na perspectiva do espectador, mas a esquematização representativa de uma ação no tempo pelo antropólogo, a partir do conjuntos de seus elementos unidos na simultaneidade.

A fase de elaboração do roteiro de edição focaliza claramente esta polêmica. A imagem técnica, no plano de uma esquematização representativa, da interiorização das ações vividas pelo antropólogo durante o processo de pesquisa de campo, passa à manipulação conceitual da linguagem, pela reconstrução, num plano superior, da narrativa etnográfica, irredutível ao plano anterior.

Pela via de um lenta e laboriosa passagem da ação ao pensamento, a imagem técnica adquire a propriedade de um conceito ao acarretar, no plano da narração, não só pela escolha

\footnotetext{
31 A propósito das citações aqui referidas de J. Piaget, A Epistemologia Genética, SP, Abril Cultural, 1978, ver seus comentários a respeito dos problemas epistemológicos clássicos.
} 
de ligações duráveis entre as ações dos personagens capazes de transpor, através das imagens em movimentos numa tela, os fragmentos vividos de suas histórias numa obra coerente, mas também nos termos da natureza de suas classificações em "coleções figurais" (convergentes por suas diversas naturezas) dispostas num contínuo.

A imagem técnica aqui se adensa e remete o antropólogo a uma relação com o fora, para além da sua "consciência psicológica íntima", capaz de restituir ao relato etnográfico uma reversibilidade operatória que o leva a se libertar do contexto original das ações do sujeito do investigador em campo e do domínio da própria causalidade de suas operações com o seu objeto. ${ }^{32}$

\section{As lógicas da identidade e da exclusão na produção de etnografias visuais}

Interrogar-se acerca da imagem técnica na formulação das categorias de entendimento antropológica no momento da produção de narrativas etnográficas através das tecnologias visuais remete, certamente, a pensar a gênese dos seus conceitos científicos em Antropologia e as transformações nas suas construções cognitivas no que concerne a seu esforço em superar os limites epistemológicos que cercam a imagem no pensamento ocidental. ${ }^{33}$

Para se precisar, portanto, os termos através dos quais se delimita o campo disciplinar da Antropologia visual, há que se tematizar as especulações evolucionistas e positivistas, que constituíram o triunfo das explicações científicas histórico-causais na compreensão do pensamento humano para, finalmente, daí se retirar as obras etnográficas do gueto formal de categorias de pensamento vazias de significação que as submete a um empirismo lógico.

Neste plano de ação, repensar as temáticas centrais da Antropologia a partir do emprego de tecnologias audiovisuais na construção de narrativas etnográficas deveria conduzir ao abandono da perspectiva que insiste na conversão do semantismo dos símbolos que configuram as operações estruturantes da imagem numa sintaxe pelo retorno ao estudo aprofundado da dinâmica incessante da linguagem e ação humanas e do instrumento de suas operações com o real.

\footnotetext{
${ }^{32}$ Num sentido inverso do autor, talvez seja interessante aqui se repertoriar os comentários criteriosos de G. Deleuze, L'image-temps, op. cit. p. 210, sobre como a matéria sinalética da imagem-movimento atinge o tema do monólogo interior na construção de narrativas etnográficas. Seria necessário se pensar quando, na produção/geração de etnografias em Antropologia visual, o antropólogo atinge uma modalidade teoremática, ou seja, quando as relacões do pensamento na imagem substituem a contiguidade das relacões de imagens. O que, para Artaud, apud G. Deleuze, significaria não se estar mais contando uma história mas se desenvolvendo "uma sequiência de estados de espírito que se deduzem uns dos outros como o pensamento se deduz do pensamento".

${ }^{33} \mathrm{Da}$ Antigüidade à Renascença, passando pela filosofia oculta e a teosofia árabe, é necessário se assinalar que o Ocidente judeu-cristão debateu-se com desconfiança em torno da Imagem como topos fantástico, como reino da imaginação e da fantasia que anuncia/denuncia a presença do mistério da criação, cf. Védrine, Les Grandes Conceptions..., op. cit.
} 
$\mathrm{Na}$ base deste processo, é necessário remarcar o lugar da imagem e da técnica que desde há muito, na Modernidade triunfante, tem se desenvolvido sob o primado do materialismo dogmático. O uso das tecnologias audiovisuais, em adesão ao dogmatismo da letra, tem, inúmeras vezes, impregnado a prática antropológica no sentido de reforçar o princípio de identidade que reina no tratamento unívoco da imagem e o seu referente material, sob o primado da exclusão das operações cognitivas e dos esquemas de pensamento que the dão suporte e de suas transformações temporais inerentes em termos da incessante troca entre as pulsões subjetivas humanas e as pressões objetivas do mundo.

De maneira geral, a Antropologia Visual, sem debruçar-se sobre o tema da imaginação e seu dinamismo organizador do pensamento humano, tende a afastar-se de uma profícua discussão acerca da gênese da figura do antropólogo no trajeto de construção da figura de homem no Ocidente. Nos termos deste afastamento, aprofundar a visão de sujeito epistêmico à qual a Antropologia, pelo via de um agnosticismo materialista que afirma a imagem como simulação da própria vida, significaria, por exemplo, denegar o concurso da imaginação criadora que a técnica e a imagem sinalizam, nos dias hoje.

Não é sem motivos que a fascinação do antropólogo em conduzir histórias humanas sob os efeitos do sentimento de realidade que detém a força da imagem-técnica, no sentido de restituir o real da vida, se transforma no momento em que o roteiro e a montagem de um vídeo ou filme etnográfico realizam a passagem definitiva da participação da imagem de recurso metodológico à sua função narrativa propriamente dita. ${ }^{34}$

Gera-se aí um mal-estar! É o momento em que o antropólogo se descobre preenchendo, com seus esquemas de pensamento em forma de narração, os intervalos do decurso do tempo que vão das séries fragmentadas de registros obtidos em campo aos efeitos de composição de uma obra. Da mesma forma, é o momento em que a imagem técnica desempenha, no plano formal da etnografia, o dinamismo integrador de abstrações formalizantes suficientemente fortes a ponto de configurar uma história una e completa a partir de incidentes e acontecimentos dispersos dispostos numa sucessão de cenas e de planos, trazendo, finalmente, um "suplemento de alma" ao métier do antropólogo.

Face à ameaça de dissolução do campo etnográfico, neste momento, o antropólogo reage. Congelando suas formulações conceituais numa pedagogia da imagem, a narrativa por ele construída tende a tornar-se discurso, dispondo ao antropólogo simetricamente os acontecimentos, as situações e os personagens, um ao lado do outro. A obra que daí resulta

\footnotetext{
${ }^{34}$ Ver a respeito Feldamn-Bianco, B. "Reconstruindo a saudade portuguesa em vídeo: histórias orais, artefatos visuais e tradução de códigos culturais na pesquisa etnográfica”. In: Horizontes Antropológicos, Ano 1, No 2, EDUFRGS, POA, 1995.
} 
não se desgruda de um realismo da imagem corpórea dos fatos, situações e acontecimentos registrados, e a ação contada se desenrola sem apontar para as mudanças interiores que subjazem à conduta dos protagonistas numa forma alusiva à imagem como "conceito". Movido pela motivação reducionista que a presença objetiva da imagem apresenta, ignorando o seu duplo (as suas forças alusivas no plano de uma fantástica transcendental), o antropólogo sucumbe à crença da "neutralidade"/ "objetividade" das concepções científicas, produzindo uma obra que se pretende domesticar a poèsis que a sustenta.

Paradoxalmente, quanto mais a verossimilhança da narrativa visual com o vivido humano é intencionada e projetada pela neutralidade dos devaneios do antropólogo, mais ela reafirma o lugar da sua imaginação criadora na produção/geração de conhecimento. Neste ponto, afastar-se do campo "ficcional" pela busca incessante da imagem enquanto semelhança do real e da vida é imaginar que há um sentido imanente nas coisas retratadas por ela, sentido que o espectador captaria na transparência do "olhar antropológico"; é enredarse, novamente, numa operação fantástica com o real onde a imagem desempenha o papel de cópia autêntica e fiel da vida.

Em Antropologia visual, a arte da ficção pode estar dissimulada sob o véu de uma motivação realista onde a etnografia visual aparece não só como semelhança com o real, mas com o verdadeiro, e onde a imagem técnica não foge ao solo fértil da imaginação criadora do pesquisador, sendo tratada como miniaturização do mundo.

Sob este ângulo, as obras etnográficas geradas no âmbito da Antropologia visual tendem a perder a sua força criadora pela tendência a submeter as imagens, no corpo de uma narrativa, a cadeias lineares e homogêneas de sentido, onde o pluralismo de suas conexões simbólicas cede lugar à intenção do antropólogo em agrupá-las segundo cifras normalizadas por um logos abstrato e vazio e delas retirar a identidade dos dados empíricos apresentados.

Aprisionado num contexto de "solidificação do mundo", o antropólogo tende a apostar no domínio do aparato tecnológico como instrumento que "nivela" a imagem ao mundo das coisas, esquecendo as operações cognitivas que the dão suporte pelo fato de que ela, denunciando sua abstração formalizante, anuncia a presença-ausência da coisa retratada. Neste caso, o mundo das aparências é tomado como único mundo existente e as formas geradas pelas tecnologias audiovisuais, fiéis às aparências, são tomadas como "reais", anunciando-se, ao nível das estruturas de conhecimento, uma dicotomia entre o mundo das formas e das essências.

Partindo-se da idéia segundo a qual existe separação entre as estruturas objetivas do mundo e as estruturas subjetivas do conhecimento humano, cria-se um fosso entre forma e 
matéria do pensamento no corpo de uma reflexão antropológica acerca das abstrações refletidoras que a imagem condensa, cindida entre os atributos do sonho e a precisão do real. Pensamento em conformidade com o movimento de secularização, que rejeita todo a dimensão transcendente das cogitações humanas, a Antropologia visual mantém-se presa fácil do cartesianismo como sua preocupação de libertar o conhecimento humano da idéia de Cosmos. $^{35}$

Toca-se aqui no problema defensivo dos usos das tecnologias audiovisuais em Antropologia. Ou seja, a defesa da produção etnográfica tendo por fundamento a imagem técnica, sustentada no argumento bergsoniano de que a inteligência se reduz à representação em imagem, pela corporeidade do movimento da vida que condensa. Este argumento, no entanto, é frágil, pois ignora a existência de operações que subjazem o "procedimento cinematográfico da inteligência”, concebida apenas como ação sobre a matéria.

Neste sentido, o campo da composição narrativa, as tecnologias audiovisuais desafiam a Antropologia visual a reaver o tratamento da dialética temporal que funda as coordenações gerais da produção da obra etnográfica (reunir, ordenar, pôr em correspondência) nas quais subsistem as estruturas dinâmicas da inteligência humana. No plano formal, a narrativa etnográfica em Antropologia encerra uma "arte de imitar a vida" pela intenção mimética do etnógrafo de copiar a experiência empírica, através de jogos de convenções, onde a consciência da ilusão não pode, por seu assujeitamento aos efeitos da linguagem, libertar-se do próprio ato interpretativo. ${ }^{36}$

O problema que se coloca para a Antropologia visual é, portanto, a aceitação de as obras etnográficas que têm por suporte do pensamento as tecnologias visuais reunirem o conjunto dos possíveis de um determinado nível de fidelidade ao dado empírico restrito ao suporte da escrita num conjunto hierarquicamente distinto das possibilidades contidas na etnografia clássica, em conseqüência, operatoriamente novas. Isto posto, sai-se da combinatória das operações cognitivas anteriores e adentra-se no plano das invenções de novos conhecimentos, aceitando-se, em decorrência, que o processo de objetivação do

\footnotetext{
35 Período da ortodoxia da Igreja, o tema da imaginação vem associado ao fenômeno da crença (podendo influenciar a crença em espíritos e demônios), vista como poder de ilusão, manipulando mitos e milagres, e como verdade, do ponto de vista do que investe num objeto uma verdade.

${ }^{36}$ Neste ponto, Kant avança sobre o pensamento de Descartes em sua tentativa de elucidar o estatuto da imaginação na formulação do conhecimento humano. O pensamento kantiano insiste no caráter construtivo da Imaginação, pois permite diferentes sínteses a priori de se efetuarem, sendo uma possibilidade da objetividade do pensamento, cf. E. Cassirer $L a$ philosophie des formes symboliques, Vol. I, Paris, Editions de Minuit, 1972. Atualmente, em termos piagetianos, poder-se-ia se reclamar a ausência da referência à ação como mediadora deste processo de formação de conceitos tanto quanto em termos vigotskinianos se demandar aí o lugar da linguagem.
} 
pensamento, "seu universo de res”, possui vias "múltiplas, irredutíveis e divergentes" de realização. ${ }^{37}$

${ }^{37}$ Cf. G. Durand, Science de l'homme et...., op. cit. 


\section{REFERENCIAS}

BACHELARD, G. La dialectique de la durée,. Paris, PUF, 1989.

BACHELARD, G. La poétique de la rêverie. Paris, PUF, 1983.

BARTHES, R. La poétique du récit. Paris, Seuil, 1997.

BRUNO, G. Sobre o Infinito. São Paulo, Abril Cultural, 1978.

ECKERT, Cornelia. et alli, "Inventariando a grafia da luz nas dissertações do PPG em Antropologia Social/UFRGS", In: Horizontes Antropológicos, Ano III, No 7, PPGAS, POA, 1997.

CASSIRER, E. La philosophie des formes symboliques. Vol. I, II III. Paris, Editions de Minuit, 1972.

CASSIRER, E. A filosofia do Iluminismo. Campinas, Ed. UNICAMP, 1994.

CORBIN, H. Avicenne et le récit visionaire. Paris, Berg International, 1979.

CORBIN, H. "Mundus imaginalis ou l'imaginaire et 'imaginal". In Cahiers International du Symbolisme, Paris, 1964.

CORBIN, H. Histoire de la philosophie islamique. Paris, Gallimard, 1964. CORBOZ, A et alli, Ciência e Imaginário. Brasília, Ed. UnB,

1994. DELEUZE, G. L'image-temps. Paris, Editions Minuit, 1985.

DURAND, G. A Fé do Sapateiro. Brasília. Ed. UnB, 1995.

DURAND, G. L'imagination symbolique. Paris, PUF, 1989.

DURAND, G. Les structures anthropologiques de l'Imaginaire. Paris, Dunod, 1984.

DURAND, G. Science de l'homme et Tradition. Paris, Berg International, 1979.

FELDAMN-BIANCO, B. 'Reconstruindo a saudade portuguesa em vídeo: histórias orais, artefatos visuais e tradução de códigos culturais na pesquisa Etnográfica". In: Horizontes Antropológicos, Ano 1, No 2, n. 6, EDUFRGS, POA, 1995.

FERRY, L. Homo Estheticus, línvention du goût à l'âge démocratique. Paris, Grasset, 1990.

GUÉNON, R. La Régne de la Quantité et les signes du Temps . Paris, Gallimard,1972

GUÉNON, R._Orient et Occident. Paris, Ed. De la Maisnie, 1987.

LEROI-GOURHAN, A Le geste et la parole. Vol I e II.. Paris, Albin Michel, 1964.

MACHADO, A Pré-cinemas \& pós-cinemas”. Campinas, Papirus, 1997.

PIAGET, J. A Epistemologia Genética, SP, Abril Cultural, 1978.

PIAGET, J. Sabedoria e Ilusões da Filosofia, SP, Abril Cultural, 1978.

RICOEUR, P. O si mesmo como um outro. Campinas, Papirus, 1994.

RICOEUR, P. Tempo e Narrativa. Vol. I, II e II. SP, Papirus, 1994.

SUBIRATS, E. A cultura como espetáculo. SP, Nobel, 1990.

TOURRAINE, A Crítica a Modernidade. Vozes, Petrópolis, 1995.

VÉDRINE, H. Les Grandes Conceptions de L'Imaginaire, de Platon à Sartre et Lacan

. Paris, Librairie Générale Française, 1990. 